\title{
SÍNTESE DO MIRISTATO DE ISOPROPILA CATALISADA POR LIPASE DE Candida rugosa IMOBILIZADA EM PARTÍCULAS MAGNETIZADAS DE ESTIRENO E DIVINILBENZENO
}

\author{
C. A. P. Souza ${ }^{1}$, M. V. C. $\operatorname{SILVA}^{1}$, L. Freitas ${ }^{1}$ \\ ${ }^{1}$ Universidade de São Paulo, Escola de Engenharia de Lorena \\ E-mail para contato: caioprudente@gmail.com
}

\begin{abstract}
RESUMO - As melhores condições da síntese do miristato de isopropila empregando lipase de Candida rugosa imobilizada por adsorção física em partículas magnéticas de poli(estireno-co-divinilbenzeno) foi determinada empregando a técnica do planejamento de experimentos. $\mathrm{O}$ suporte foi sintetizado via polimerização em suspensão e magnetizado pela adição de íons $\mathrm{Fe}^{2+} \mathrm{e} \mathrm{Fe}^{3+}$. A influência da razão molar entre o ácido e o álcool e da temperatura foi avaliada em experimentos realizados segundo um planejamento experimental $2^{2}$ estrela rotacional com 4 pontos axiais e 3 replicatas no ponto central. A partir da análise estatística (95\% de confiança), verificou-se que somente a razão molar foi significativa, apresentando influência marcante na síntese do éster, obtendo-se $83 \%$ de rendimento teórico em 9 h de reação.
\end{abstract}

\section{INTRODUÇÃO}

O Brasil é o pais que apresenta uma das maiores biodiversidades do planeta, porém a utilização de recursos não sustentáveis ainda contempla grande parte da sua economia. Assim, é necessário que haja um avanço nas pesquisas sustentáveis, sendo a biotecnologia, apresentada como uma alternativa para essa mudança no panorama econômico brasileiro. Estima-se que no ano de 2020, 20\% dos produtos químicos serão resultantes de processos biotecnológicos (Gonçalves, 2013).

Uma importante área da biotecnologia é a implementação de processos enzimáticos, que vem se destacando como uma alternativa promissora pra a substituição de processos convencionais. No entanto, tais processos apresentam algumas desvantagens como a dificuldade de recuperação da enzima, solubilidade em alguns meios reacionais e instabilidade concernente a temperatura e $\mathrm{pH}$. Para solucionar esses problemas a técnica de imobilização de enzimas vem sendo cada vez mais estudada e utilizada (De Castro et al., 2010).

Atualmente, diversos materiais são utilizados como suporte para imobilização de enzimas. Dentre eles, destaque especial pode ser dado ao copolímero de estireno e divinilbenzeno magnetizado, por apresentar algumas vantagens em relação aos demais suportes, tais como: elevada área superficial para imobilizar a enzima, maior estabilidade com relação a temperatura e ao $\mathrm{pH}$ e facilidade de recuperação do biocatalizador (Ren et al., 2011). 
A esterificação de ésteres de cadeia longa é uma das diversas reações as quais as lipases podem catalisar. Estes ésteres são classificados como ésteres emolientes e são vastamente utilizados nas indústrias de cosméticos, de alimentos e de lubrificantes. O miristato de isopropila apresenta excelente espalhabilidade e uma boa absorção pela pele, sendo muito utilizado em coposições cosméticas em aplicações skincare (Raajeshkumar; Annamma; Arvind, 2015).

Convencionalmente o miristato de isopropila é obtido sob altas temperaturas, tendo como resultado um produto com cor e odor indesejável, necessitando de etapas de purificação e refinamento (Khan et al., 2015). Nesse contexto, o presente trabalho teve como objetivo estudar a influência da temperatura e da razão molar entre os materiais de partida na síntese do miristato de isopropila catalisada pela lipase de Candida rugosa imobilizada em poli(estireno-co-divinilbenzeno) magnetizado, sendo os resultados avaliados por análise estatística.

\section{MATERIAIS E MÉTODOS}

\subsection{Materiais}

Foi usada a lipase microbiana de Candida rugosa (tipo VII, Sigma-Aldrich®) na forma imobilizada através do método de adsorção física em poli (estireno-co-divinilbenzeno)

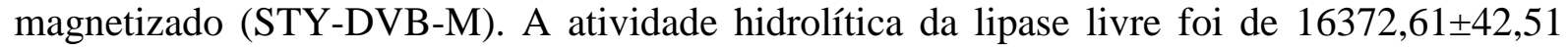
$\mathrm{U} \cdot \mathrm{g}^{-1}$. Como materiais de partida foram empregados ácido mirístico (Cromoline) e isopropanol (Cromoline) em meio heptano (Cromoline). Para a realização das dosagens de atividade enzimática foram utilizados azeite de oliva comercial com baixo teor ácido (Carbonell) e goma arábica em pó pura (Synth).

\subsection{Síntese do suporte polimérico magnetizado (STY-DVB-M)}

O suporte de STY-DVB foi sintetizado através da técnica de polimerização em suspensão de acordo com Bento et al. (2017), sendo adicionada 10\% (m/m) de magnetita obtida pelo método de co-preciptação dos íons $\mathrm{Fe}^{+2}$ e $\mathrm{Fe}^{+3}$ em meio básico. A magnetita foi previamente tratada com ácido oleico segundo a metodologia descrita por Lee et al. (2003). As partículas obtidas foram peneiradas e as retidas entre as peneiras de 24 e 80 Mesh (Tyler) foram escolhidas para a realização da imobilização.

\subsection{Imobilização da lipase de Candida rugosa no suporte polimérico}

A imobilização foi realizada via adsorção física, em uma proporção mássica de 1:4 (enzima:suporte) em meio heptano, juntamente com solução aquosa $5 \mathrm{~g} \cdot \mathrm{L}^{-1}$ de polietilenoglicol $\left(100 \mu \mathrm{L}\right.$ por grama de suporte) por $24 \mathrm{~h}$ a $4{ }^{\circ} \mathrm{C}$. O biocatalisador foi recuperado por filtração à vácuo seguido de lavagens com heptano até umidade inferior a $10 \%$ (Bento et al., 2017)

\subsection{Dosagem da atividade hidrolítica}


A atividade hidrolítica do biocatalisador foi quantificada pelo método de hidrólise do azeite de oliva de acordo com Soares et al. (1999). O rendimento de imobilização ( $\eta \%)$ foi calculado pela relação de unidades de atividade oferecidas para imobilização e a quantidade recuperada pelo derivado imobilizado.

\subsection{Síntese do miristato de isopropila}

O substrato foi preparado utilizando ácido mirístico e álcool isopropílico em meio heptano, empregando peneira molecular (tipo pellets, Sigma-Aldrich ${ }^{\circledR}$ ) ativada em mufla numa relação de $10 \%(\mathrm{~m} / \mathrm{v})$ e armazenado em refrigerador na temperatura de $4-8^{\circ} \mathrm{C}$ por 18 horas.

Os experimentos foram realizados de acordo com o planejamento estatístico $2^{2}$ estrela rotacional com 4 pontos axiais e 3 replicatas no ponto central, conforme indicado nas Tabelas 1 e 2. As reações de esterificação foram conduzidas em Shaker sob agitação de $200 \mathrm{rpm}$ e temperaturas variadas, em fracos de vidro contendo $20 \mathrm{ml}$ de substrato e $12,5 \%(\mathrm{~m} / \mathrm{v})$ de biocatalisador. Em tempos pré-determinados, foram retiradas alíquotas para quantificar o consumo do ácido por meio da titulação com hidróxido de potássio $0,02 \mathrm{~mol} \cdot \mathrm{L}^{-1}$.

Tabela 1 - Variáveis e níveis utilizados no planejamento de experimentos $2^{2}$ estrela rotacional para a síntese do miristato de isopropila.

\begin{tabular}{c|c|cccccc}
\hline \multicolumn{7}{c}{ Variáveis } & \multicolumn{7}{c}{ Níveis } \\
\hline Reais & Codificadas & $\mathbf{- \alpha}$ & $\mathbf{- 1}$ & $\mathbf{0}$ & $\mathbf{1}$ & $\mathbf{+ \alpha}$ \\
& & $(\mathbf{- 1 , 4 1 4 )}$ & & & & $\mathbf{( 1 , 4 1 4 )}$ \\
\hline Temperatura $\left({ }^{\circ} \mathbf{C}\right)$ & A & 35,9 & 38 & 43 & 48 & 50,1 \\
Razão molar (ácido:álcool) & B & $1: 2,20$ & $1: 1,25$ & $1,65: 1$ & $2,5: 1$ & $2,85: 1$ \\
\hline
\end{tabular}

Tabela 2 - Matriz experimental do planejamento de experimentos $2^{2}$ estrela rotacional para a síntese do miristato de isopropila.

\begin{tabular}{ccc}
\hline Ensaios & $\begin{array}{c}\text { Temperatura } \\
\left({ }^{\circ} \mathbf{C}\right)\end{array}$ & $\begin{array}{c}\text { Razão Molar } \\
(\text { Ácido/ Álcool) }\end{array}$ \\
\hline 1 & 48,0 & $1: 1,25$ \\
2 & 38,0 & $1: 1,25$ \\
3 & 43,0 & $1: 2,20$ \\
4 & 48,0 & $2,50: 1$ \\
5 & 38,0 & $2,50: 1$ \\
6 & 43,0 & $2,85: 1$ \\
7 & 50,1 & $1,65: 1$ \\
8 & 35,9 & $1,65: 1$ \\
9 & 43,0 & $1,65: 1$ \\
10 & 43,0 & $1,65: 1$ \\
11 & 43,0 & $1,65: 1$ \\
\hline
\end{tabular}




\section{RESULTADOS E DISCUSSÕES}

\subsection{Atividade hidrolítica e rendimento da imobilização}

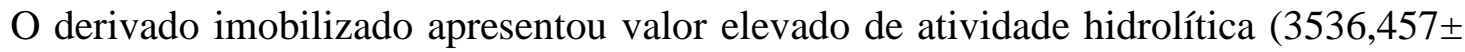
$154,722 \mathrm{U} \cdot \mathrm{g}^{-1}$ ) e de rendimento de imobilização (95,94\%), demonstrando viabilidade de aplicação do suporte magnético sintetizado e a eficácia do método de imobilização proposto.

\subsection{Estudo da influência da temperatura e da razão molar na síntese do miristato de isopropila}

Visando verificar a influência dos fatores: temperatura e razão molar na síntese do palmitato de isopropila catalisada pela lipase de Candida rugosa imobilizada em STY-DVB$\mathrm{M}$, foi realizado um planejamento experimental $2^{2}$ estrela rotacional com 4 pontos axiais e 3 replicatas no ponto central, tendo como variável resposta o rendimento teórico da reação, ou seja, considerando que todo o reagente limitante foi convertido à éster. A Figura 1 ilustra o perfil dos rendimentos teóricos obtidos nos ensaios efetuados.

Nota-se que os melhores rendimentos foram obtidos para os ensaios 5, 6 e 7, atingindo um máximo de $80 \%$ em 9 h de reação. Estes testes foram realizados com as razões molares mais elevadas previstas no planejamento estatístico e sob temperaturas variadas, indicando que o excesso do ácido graxo favoreceu a síntese do éster.

Figura 1 - Perfil dos rendimentos teóricos obtidos para os ensaios realizados a partir do planejamento de experimentos $2^{2}$ estrela rotacional para a síntese do miristato de isopropila.

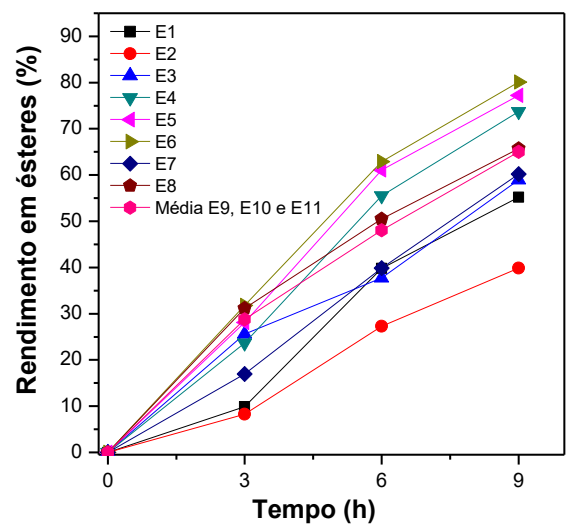

Para a realização da análise estatística foram empregados os softwares Statistica versão 12 (StatSoft Inc., USA) e Design-Expert 10.0 (Stat-Ease Corporation, USA). A Figura 2a mostra o gráfico de Pareto obtido pela análise estatística, apresentando como efeito significativo apenas o termo linear da razão molar $(4,92)$, confirmando que a temperatura não é significativa para a síntese do miristato de isopropila. Esse fato pode ser explicado devido à maior estabilidade conferida à enzima pelo processo de imobilização, tornando-a mais estável termicamente.

A Tabela 3 apresenta a análise de variância (ANOVA), cujo modelo estatístico 
proposto (Equação 1), mostrou-se significativo ao nível de $95 \%$ de confiança, não sendo constatada falta de ajuste. A Figura 2 b ilustra a superfície de resposta gerada a partir dos dados estatísticos obtidos, na qual é possível notar que os maiores valores de rendimento teórico encontram-se na região com razões molares (ácido:álcool) maiores que 2:1 e temperaturas mais amenas.

Figura 2 - a) Gráfico de pareto e b) Superfície de resposta obtido pela análise estática do planejamento de experimentos $2^{2}$ estrela rotacional para a síntese do miristato de isopropila.
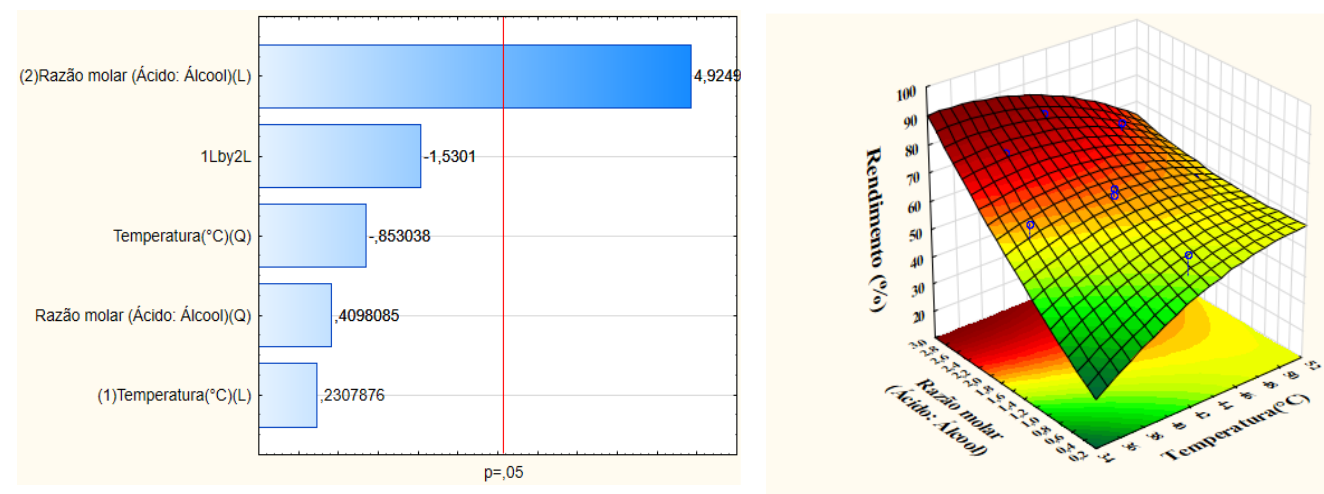

Tabela 3 - ANOVA dos resultados obtidos a partir do planejamento $2^{2}$ estrela rotacional.

\begin{tabular}{lccccc}
\hline $\begin{array}{l}\text { Fonte de } \\
\text { variação }\end{array}$ & $\begin{array}{c}\text { Soma } \\
\text { Quadrática }\end{array}$ & $\begin{array}{c}\text { Grau de } \\
\text { Liberdade }\end{array}$ & $\begin{array}{c}\text { Média } \\
\text { Quadrática }\end{array}$ & F & P \\
\hline Modelo & 1058,51 & 5 & 211,70 & 5,57 & $0,0413^{*}$ \\
A-Temperatura & 2,02 & 1 & 2,02 & 0,05 & 0,8266 \\
B- Razão Molar & 921,65 & 1 & 921,65 & 24,26 & $0,0044^{*}$ \\
AB & 88,96 & 1 & 88,96 & 2,34 & 0,1865 \\
A $^{2}$ & 27,65 & 1 & 27,65 & 0,73 & 0,4326 \\
B $^{2}$ & 6,38 & 1 & 6,38 & 0,17 & 0,6989 \\
Resíduo & 189,99 & 5 & 38,00 & & \\
Falta de Ajuste & 177,96 & 3 & 59,32 & 9,86 & 0,0935 \\
Erro Puro & 12,03 & 2 & 6,02 & & \\
Cor Total & 1248,50 & 10 & & & \\
\hline
\end{tabular}

$* \mathrm{p}<0,05$

$\mathrm{Y}=-197.47160+9.49469 * \mathrm{~A}+55.48197 * \mathrm{~B}-1.10964 * \mathrm{~A} * \mathrm{~B}-0.087947 * \mathrm{~A}^{2}+1.47605 * \mathrm{~B}^{2}$

(Eq. 1)

Em que Y representa o rendimento teórico da reação, A é o valor codificado da variável temperatura $\left({ }^{\circ} \mathrm{C}\right)$ e B é o valor codificado da variável razão molar.

Com o auxílio do programa estatístico Design-Expert 10.0, foi possível encontrar a condição ótima de razão molar e temperatura para a obtenção do maior rendimento em éster, dentro da faixa do estudo realizado. As condições experimentais ótimas indicadas foram: razão molar (ácido: álcool) de 2,79:1 e temperatura de $39,0^{\circ} \mathrm{C}$, tendo como resposta, um rendimento de $84,57 \%$. Para a confirmação do modelo, foi realizado um ensaio nessas 
condições, que atingiu 83,10\% de rendimento em 9 horas de reação, apresentando um desvio em relação ao valor predito do modelo de 1,74\%, considerado plenamente satisfatório.

\section{CONCLUSÃO}

Os resultados obtidos mostraram que a lipase de Candida rugosa imobilizada em poli (estireno-co-divinilbenzeno) magnetizado apresenta potencial de aplicação industrial na síntese de ésteres emolientes, atingindo rendimentos superiores a 80\% empregando temperaturas amenas $\left(39{ }^{\circ} \mathrm{C}\right)$. Pela análise estatística, foi possível constatar que apenas a razão molar do substrato foi significativa e influenciou de forma positiva a síntese do miristato de isopropila, sendo os maiores rendimentos obtidos em níveis mais elevados de razão molar (2,79:1). Além disso, o derivado imobilizado apresentou elevada atividade hidrolítica $(3536,457 \pm 154,722 \mathrm{U} \cdot g-1)$ e alto rendimento de imobilização $(95,94 \%)$.

\section{REFERÊNCIAS}

BENTO, H.B.S.; DE CASTRO, H.F; OLIVEIRA P.C.; FREITAS, L. Magnetized poly(STY-co-DVB) as a matrix for immobilizing microbial lipase to be used in biotransformation. J. Magn. Magn. Mater., v. 426, p. 95-101.

DE CASTRO, H. F.; MENDES, A. A.; FREITAS, L.; SANTOS, J. C. Modificação enzimática de óleos e gorduras para a obtenção de biocombustíveis e produtos de interesse do setor alimentício. In: Biocatálise e Biotransformação - Fundamentos e Aplicações. 1 ed. São Paulo: Schoba, 2010, v.1, p.275-337.

GONÇALVES, C. G. S.; MARSAIOLI, A. J. Fatos e Tendências da biocatálise. Quim. Nova, v. 36, n. 10, p.1587-1590, 2013.

KHAN, N. R.; RATHOD, V. K. Enzyme catalyzed synthesis of cosmetic esters and its intensification: A review. Process Biochem., v. 50, p. 1793-1806, 2015.

LEE, Y.; RHO, J.; JUNG, B. Preparation of Magnetic Ion-Exchange Resins by the Suspension Polymerization of Styrene with Magnetite. J. Appl. Polym. Sci., v. 89, p. 2058-2067, 2003.

SOARES, C.M.F.; DE CASTRO, H.F.; MOARES, F.F.; ZANIN, G.M., Characterization and utilization of Candida rugosa lipase immobilized on controlled pore silica. Appl. Biochem. Biotechnol., v. 77, p. 745-757, 1999.

RAJESHKUMAR, N. V.; ANNAMMA, A. O., ARVIND, M. L. Green synthesis of isopropyl myristate in novel single phase medium Part II: Packed bed reactor (PBR) studies. Biotechnol. rep., v. 8, p. 105-109, 2015.

REN, Y.; RIVERA, J. G.; HE, L.; KULKARNI, H.; LEE, D.; MESSERSMITH, P. B. Facile, high efficiency immobilization of lipase enzyme on magnetic iron oxide nanopartocles via a biomimetic coating. BMC Biotechnol., 11, 1-8, 2011. 